\title{
Applied Linguistics from the Perspective of Sign Language and Deaf Studies
}

\author{
Bencie Woll, University College London
}

\section{Introduction}

This chapter begins with an introduction to the linguistic study of sign languages, including a review of the status of sign languages within their surrounding majority spoken language communities and a brief description of current research priorities in the applied linguistics of sign language. These include sign language teaching and learning, language and politics, sign language within the bilingual context, and technological and social change. It will conclude with a summary as to the role of applied linguistics in identifying and solving problems in relation to sign languages (both linguistic and policy-oriented).

Sign languages are not related to or derived from spoken languages; they use the visual-spatial modality; they have their own lexicons and grammars. There are many different sign languages in the world. Unrelated sign languages are mutually unintelligible. Around 200 are listed in Ethnologue. It is certain that there are more sign languages: the current number reflects the relatively recent interest in sign languages.

Contrary to common belief, sign languages are natural languages, which develop within a community of deaf individuals. They are not universal, they

How to cite this book chapter:

Woll, B. 2019. Applied Linguistics from the Perspective of Sign Language and Deaf Studies. In: Wright, C., Harvey, L. and Simpson, J. (eds.) Voices and Practices in Applied Linguistics: Diversifying a Discipline, pp. 51-70. York: White Rose University Press. DOI: https://doi.org/10.22599/BAAL1.d. Licence: CC BY-NC 4.0 
are not invented by hearing people to aid in the education of deaf children, they are not pantomime, and they are not a manual representation of the spoken or written language. The failure to recognise that sign languages are languages is quite striking. Among the many maps of the languages of Europe that are available on the internet, none includes sign languages, although the distribution of sign languages does not follow the boundaries associated with spoken languages. For example, Irish Sign Language is not a sign language associated with the Gaelic-speaking population of Ireland but is instead the language used by the Catholic population of both Northern Ireland and the Republic of Ireland, while British Sign Language is used by Protestants in the North. The two languages are not historically related, with Irish Sign Language being a descendant of French Sign Language.

\section{How deaf communities and sign languages arise}

Deaf communities have their origins in the small number of families with multigenerational deafness and also where deaf people have the opportunity to come in contact with each other. Although the most common context for this is the establishment of schools for deaf children, there are historical records of other settings in which sign languages may have their beginnings. Examples can be found in the British context. One is in a book by Richard Carew, The History of Cornwall, published in 1602, in which an account is given of a deaf man, Edward Bone, communicating with a deaf friend:

Edward Bone, of Ladock in this county, was servant to Mr. Courtney therein. He was deaf from his cradle, and consequently dumb (Nature cannot give out where it hath not received); yet could learn, and express to his master, any news that was stirring in the country; There was one Kempe, not living far off, defected accordingly, on whose meetings there were such embracements, such strange, often, and earnest tokenings, and such hearty laughters, and other passionate gestures, that their want of a tongue seemed rather an hindrance to others conceiving them, than to their conceiving one another.

(Carew 1602)

Another appears in the dedication of the book Philocophus, by John Bulwer, published in 1648. The book is dedicated to a deaf baronet and his deaf brother:

What though you cannot express your minds in those verball contrivances of man's invention; yet you want not speeche; who have your whole body for a tongue.

(Bulwer 1648) 
Samuel Pepys describes a conversation between a deaf boy and George Downing (after whom Downing Street in London is named) in which the unintelligibility of signing to someone who does not know the language is commented on, as well as the possibility of a hearing person learning it.

By and by comes news that the fire has slackened; so then we were a little cheered up again, and to supper, and pretty merry. But, above all, there comes in the dumb boy that I knew in Oliver's time, who is mightily acquainted here, and with Downing; and he made strange signs of the fire, and how the King was abroad, and many things they understood, but I could not, which I wondering at, and discoursing with Downing about it, 'Why', says he, 'it is only a little use, and you will understand him, and make him understand you with as much ease as may be.'

(Pepys, entry for 9 November 1666)

Deafness is statistically uncommon, with about one in 1,000 children born deaf in developed countries. In European countries, the establishment of education for deaf children in the 18 th century provided a context in which deaf children from hearing families could begin to be exposed to a sign language from an early age, and in which, because of their use as a language of instruction, sign languages began to be informally codified and transmitted from generation to generation, despite the absence of a written form, and deaf communities began to develop.

\section{Sign language and education}

Use of sign languages in education varies greatly around the world and even within countries. Since the beginning of education for deaf children some schools have used a form of sign language for instruction and some have used spoken language, relying on residual hearing, lip-reading and speaking (part of the philosophy of 'oralism'). The extensive dialect differences within many sign languages are generally school-based in origin. The regional variation in BSL can be attributed to the over 40 schools that were independently established and administered in the 19th century. Significantly, Irish SL has very little regional variation because there were only two main deaf schools in Ireland, both in Dublin. American Sign Language also has surprisingly little regional variation, given the size of the country and its deaf population, possibly because of the centralising effects of Gallaudet University and the original Hartford Asylum, where all training of teachers of the deaf took place initially.

Whether communication was primarily manual or oral, until the 1980s deaf children were usually educated in deaf schools with other deaf children and they usually learned sign language even though attitudes to signing in schools were often negative. Since the 1980s sign languages have been more accepted in 
schools, but simultaneously there has been a strong move towards mainstreaming deaf children. This has produced improvements in educational achievement but has reduced the opportunity for deaf children to join a natural signing community at an early age. Despite remarkable advances in technology, such as cochlear implants, many deaf children do not achieve age-appropriate levels of either BSL or written or spoken English.

Education in many countries has also had a profound effect on national sign languages because deaf educators took on methods of teaching and methods of communication used in other countries (see Table 1 below). LSF (French Sign Language) has had the greatest impact; its influence can be seen clearly in Irish SL (Burns 1998), ASL (Lane 1984) and Russian Sign Language (Mathur \& Rathman 1998) and in some dialects of BSL influenced by Irish SL. Other sign languages have also had this sort of influential role. For example, Portuguese signers use the Swedish Sign Language manual alphabet, because a Swedish educator helped to found a deaf school in Portugal. Irish SL, originally heavily influenced by LSF, has also had its own considerable impact on sign languages around the world. Irish nuns and Christian brothers have taught in Catholic schools for deaf children in countries including India, South Africa and Australia, and the influence of ISL is noticeable in the sign languages in these countries (Aarons \& Akach 1998).

Woodward (1996) has described how Modern Thai SL has been greatly influenced by American signs through the education system, although the original sign languages in Thailand have no influence from ASL. The sign languages in Vietnam all show strong influences from LSF, which was introduced into the first school for deaf children in Vietnam in 1886. Schermer (2004) noted that the Groningen dialect of SLN was influenced by LSF after a Dutch visit to the Paris deaf school in 1784 .

ASL, itself originally influenced by LSF, has an increasing impact on sign languages around the world. Gallaudet University attracts foreign deaf students, who take ASL back to their own countries. The USA has been especially

Table 1: Sign language families.

\begin{tabular}{|l|l|l|l|}
\hline $\begin{array}{l}\text { British Sign Language } \\
\text { (BSL) family }\end{array}$ & $\begin{array}{l}\text { Langue des signes } \\
\text { française (LSF) } \\
\text { family }\end{array}$ & $\begin{array}{l}\text { Deutsche } \\
\text { Gebärdensprache } \\
\text { (DGS) family }\end{array}$ & $\begin{array}{l}\text { Svenska } \\
\text { teckenspråk } \\
\text { (STS) family }\end{array}$ \\
\hline British & French & German & Swedish \\
\hline Australian & Russian & Austrian & Finnish \\
\hline New Zealand & American & Hungarian & \\
\hline Maltese & Irish & Danish & \\
\hline Maritime (Canada) & & Icelandic & \\
\hline
\end{tabular}


generous in providing teacher training in many Third World countries. Andrew Foster, a deaf African-American, led a movement for the establishment of schools in African countries where ASL was introduced as the language of tuition (Lane, Hoffmeister \& Bahan 1996).

Most research has been on the sign languages of North America and Europe, and small numbers of relatively well educated deaf people are spread across nations but socialise within local and national deaf communities and share a common national sign language. There are also small, isolated, often rural, communities around the world where higher rates of genetic deafness create 'deaf villages' which develop their own sign languages. These include Grand Cayman Island (Washabaugh 1981), the Urubu-Kaapor of Brazil (Ferreira-Brito 1985), the Yucatan Maya (Johnson 1994), the Enga of New Guinea (Kendon 1980), the people of Desa Kolok on the island of Bali (Branson et al. 1996) and the Al-Sayyid Bedouin in Israel (Kisch, 2007, 2008). (Also see Kusters (2009) for a comprehensive review of research on 'shared sign languages.')

In the community in Bali called Desa Kolok by Branson and colleagues, 2\% of the 2000 village residents are deaf, and marriage between hearing and deaf villagers is the norm. Deaf members of the community have equal status in decision-making at local community level, although few are reported to participate. Those who do, use family members to interpret, since not all village members are fluent in sign language. In earlier times, village deaf children received no formal education, although there has been a school for hearing children for over 50 years. Recent moves to offer specialist deaf education has resulted in the placing of deaf children in a school located outside the village, and this has begun to alter the linguistic and social dynamics of the community.

Al-Sayyid Bedouin Sign Language is used in a Bedouin tribe of around 3,000 people with approximately $5 \%$ deaf. Deaf children have in the past had better access to education than hearing children, since they attended a deaf school where Hebrew was taught. The deaf children therefore developed a degree of literacy in the majority language, which is a key to employability, and they are fully economically integrated. While all hearing members of the community have some knowledge of the tribe's sign language, only hearing people in families with a high percentage of deaf members are fully fluent.

\section{Attitudes to sign language}

There is a long history of negative attitudes to sign languages in many countries. These attitudes are very much like attitudes to other low social status minority languages:

I had a lot of punishments for signing in classrooms and at playground. ... Then one morning at assembly I was caught again, then ordered to stand in front. The headmistress announced that I looked like a monkey 
... [w] aving my hands everywhere. She [said] she will put me in a cage in the zoo so the people will laugh at a stupid boy in the cage.

(Kyle \& Woll 1985)

Educators have often compared sign languages unfavourably to European languages, suggesting that the learning of a sign language might interfere with the learning of a spoken language and noting that sign languages frequently 'lack' certain features seen in European spoken languages, such as tense, gender or determiners. This is also of course true of many spoken languages. In the following section some features of sign languages will be briefly introduced.

\section{Some linguistic features of sign languages}

Early modern research on sign languages emphasised the underlying structural similarities of spoken and sign languages, but more recent research has moved towards the recognition that there are systematic typological differences, arising mainly from the interaction of language form with modality. Phonological and morphological structures in sign languages and spoken languages differ, because sign languages have greater correspondence between form and meaning (iconicity or visual motivation) than spoken languages do. Sign languages also exploit space for grammatical purposes, creating syntactic structures exhibiting extensive simultaneity, while spoken languages prefer linearity and affixation processes. Other differences arise from the properties of the articulators (sign languages use two primary articulators the hands - as well as non-manual articulators, including the torso, head and face, eyes and mouth) and the differing properties of the visual and auditory perceptual systems.

Of course, both spoken and signed languages articulate lexical items sequentially. Spoken languages can give some linguistic information simultaneously, (as in, for example, tone languages), and prosody adds further grammatical and affective information to the lexemes uttered. Essentially, though, humans have only one vocal apparatus so spoken languages must use sequential structures. Indeed, linear syntax may be seen as a solution adopted by spoken languages to deal with the availability of only one articulatory system. The availability of two hands (and head and face) enables sign languages to use simultaneously articulated structures (see Vermeerbergen, Leeson \& Crasborn 2007). Two hands can be used to represent the relative locations of two referents in space and their spatial and temporal relationships. In representing, for example, a person reaching for a book while holding a pen, English conjoins clauses using 'while' or 'as' to indicate two events happening simultaneously. In sign languages, 'holding a pen' can be signed with one hand, while 'reaching for the book' can be signed with the other. English uses prepositions such as 'next to' or 'behind' 
to represent relative locations, whereas sign languages can simply place the two signs in the relative locations of the two referents.

In the light of these differences, linguistic theory needs to take greater account of modality (Meier, Cormier \& Quinto-Pozos 2003). Research on sign languages has also encouraged a recognition of the interrelationship of language and gesture, for example the presence of slots in discourse structure where signers can switch to gesturing, such as when they want to show the roles of characters in a story. Cognitive models are increasingly used to account for the visual motivation behind the structure and form of sign languages, irrespective of the level of language analysis (Taub 2001).

Although the social histories of sign languages differ from each other in many respects, there appears to be greater typological similarity among sign languages than among spoken languages. Their relative youth (Kegl, Senghas \& Coppola 1999) and their possible Creole status (Fischer 1978) may account for some of this, but visual motivation as an organising factor in the lexicon and syntax is also likely to be significant. The basic similarities in structure of sign languages are sufficient for us to treat them together in a brief review here. Examples are for the most part drawn from BSL.

Educators have often compared sign languages unfavourably to spoken (European) languages, noting that sign languages frequently 'lack' certain features seen in European spoken languages, such as tense, gender, or determiners. In fact, sign languages share many features with other language groups, especially other head-marking languages, such as Navajo, Mayan and Abkhaz, rather than dependent-marking languages, such as many in the Romance, Germanic and Sino-Tibetan families (Slobin 2005). For example, sign languages share features with the languages of Micronesia (Nichols 1992), including adjectives operating as intransitive verbs, distinctions between inclusive and exclusive pronouns and lack of a copula. Verbs in languages of this type (both signed and spoken) often use classifiers (based on shape or animacy, for example), show direct object incorporation, have rich inflection including aspect and show little opposition of active and passive voice.

\section{The visual modality and iconicity}

While signed and spoken languages share many grammatical features, the visualspatial modality provides structural possibilities unavailable to spoken languages.

Spoken languages can incorporate auditory features of referents into the language (as in onomatopoeia), but there are relatively few opportunities for this since humans perceive the world largely visually. In contrast, signs often represent the visual form of a referent (for example BSL TREE (Figure 1a), how it moves or where it is located. It should be noted that not all signs are visually motivated (for example, BSL SISTER (Figure 1b)). 


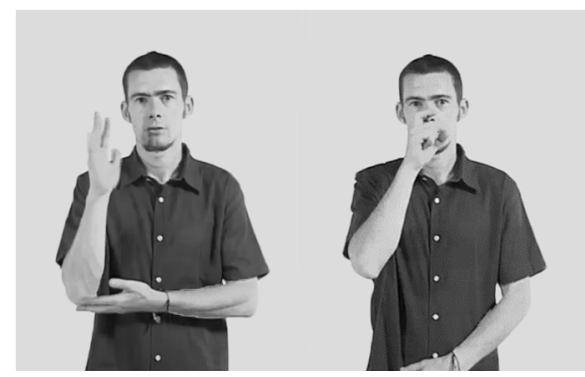

Figure 1a: TREE; Figure 1b: SISTER (Copyright BSL SignBank, University College London. Reproduced with permission of Prof. Bencie Woll).

Whether or not a sign is visually motivated, all signs exhibit a conventionalised relationship between the form and the referent. A sign can be visually motivated but the particular image selection of the referent for the linguistic encoding is arbitrary. For example, the BSL sign TEA reflects the action of drinking from a teacup, while the American sign reflects the act of dipping a teabag in a cup.

Signed languages can convey spatial relations directly. The linguistic conventions used in such spatial mapping specify the position of objects in a highly geometric and non-arbitrary fashion by situating certain sign forms (e.g., classifiers) in space such that they maintain the topographic relations of the world-space being described (Emmorey, Corina \& Bellugi 1995). Within these structures, the handshapes in verbs of motion and location in topographic sentences represent object features or classes (how objects are handled, their size and shape, or their function). These are usually termed 'classifiers' (Supalla 1986; Engberg-Pedersen 1993).

\section{Phonology}

Phonology is traditionally defined as a sublexical level of structure consisting of contrastive patterns of meaningless sounds. Can there be a 'phonology' of a soundless language?

Since Stokoe's pioneering work on ASL (1960), linguists have analysed signs as consisting of combinations of handshape configuration, a location where the sign is articulated, and movement - either a path through signing space or an internal movement of the joints in the hand. Each is understood to be a part of the phonology, because changing one of these parameters can create a minimal pair. Thus, in BSL, AFTERNOON and ORDER differ only in handshape, AFTERNOON and NAME differ only in location (Figures $2 \mathrm{a} \& 2 \mathrm{~b}$ ) and AFTERNOON and TWO-HUNDRED only in movement. There have been considerable modifications to Stokoe's framework since 1960, but this model 
has remained the basic description of sign language phonology. There is also neurobiological evidence from fMRI studies of sign language processing, that sign language phonology is processed in the same brain regions as spoken language phonology (MacSweeney et al. 2008).

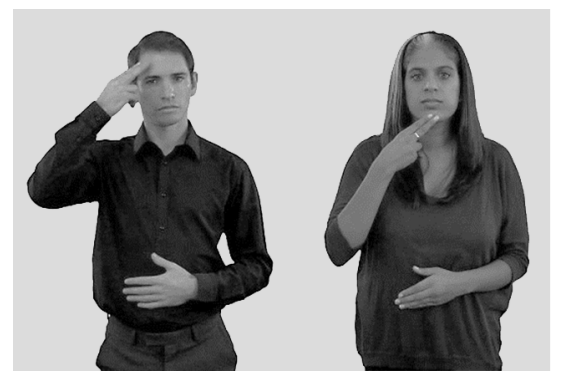

Figure 2a: NAME; Figure 2b: AFTERNOON (Copyright BSL SignBank, University College London. Reproduced with permission of Prof. Bencie Woll).

What is required for both spoken language and sign language, therefore, is a modified, modality-neutral definition of phonology: a level of grammar involving rules for combining a finite number of meaningless features into a very large number of pronounceable utterances (Brentari 2011).

\section{Morphology}

Sign language morphology tends to manifest itself in simultaneous combinations of meaningful handshapes, locations and movements. In derivational morphology, for example, handshape can change to reflect numbers - for example n-WEEKS, n-O'CLOCK and n-YEARS-OLD are articulated with conventionalised location and movement, while the handshape indicates the number. Signs referring to objects and actions may also differ only in movement, so the verbs LOCK, READ-A-NEWSPAPER and EAT are made with a single, large movement, compared to the derivationally related nouns KEY, NEWSPAPER and FOOD, which have short, repeated movements.

Verbs in SL can be morphologically complex, with three types of verbs (plain, agreeing and spatial) defined by their morphology, their semantics and the type of space they inhabit. Plain verbs often represent agent or experiencer activity; agreeing verbs usually represent transfer between agent and object; and spatial verbs represent static or dynamic location. The three types have different movement characteristics: plain verbs are often body anchored; agreeing verbs often move in the horizontal plane; spatial verbs often move in all three planes. Sign languages differ in their assignment of verbs to these classes: The BSL verb WANT is a plain verb, while ASL WANT is an agreeing verb. 
Figures 3, 4 and 5 below provide examples of each of these verb types. It can also be seen that the syntax of BSL differs systematically from English syntax, with the verb in sentence-final position.

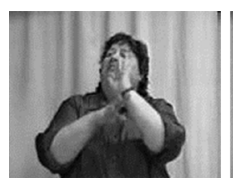

FILM

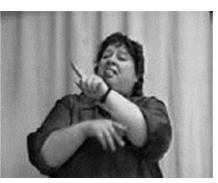

INDEX

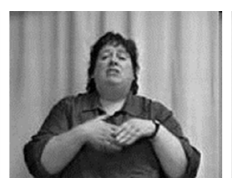

FRIEND

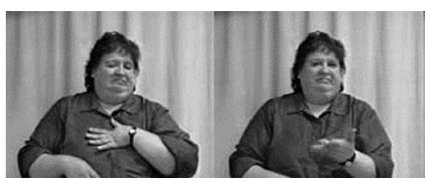

LIKE-NOT

Figure 3: Plain verb. My friend didn't like that film (Stills from unpublished video. Reproduced with permission of Prof. Bencie Woll).

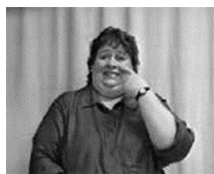

YESTERDAY

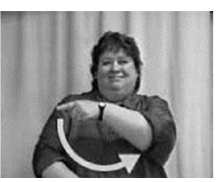

INDEX-3pl,

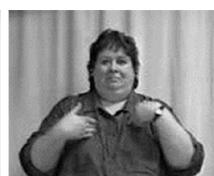

INDEX-1sg

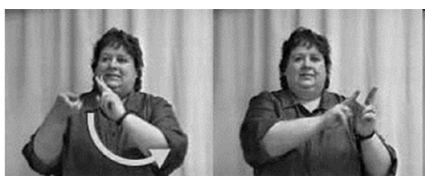

INTERPRET-3pl-obj

Figure 4: Agreeing verb. Yesterday I interpreted for all of them (Stills from unpublished video. Reproduced with permission of Prof. Bencie Woll).

The verb INTERPRET 'agrees' with the location assigned to the object 'all of them' (INDEX-3pl $\mathrm{j}_{\mathrm{j}}$

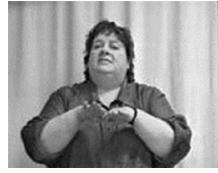

TABLE

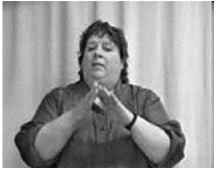

BOOK PEN LONG-THIN-OBJ-cl

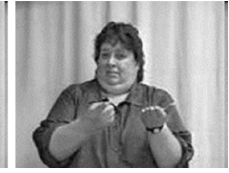

FLAT-OBJ-cl

Figure 5: Spatial verb. The pen is to the right of the book on the table (Stills from unpublished video. Reproduced with permission of Prof. Bencie Woll).

The lexical signs BOOK and PEN are replaced in the verb (LOCATED-ON) by the classifiers for FLAT-OBJECT and LONG-THIN-OBJECT, respectively, while their location is indicated by the matching of their height in space with the height of the sign TABLE.

Inflectional morphology is also shown by changes in movement and location. Thus, degree is shown through size, speed, onset speed and length of hold in a movement, with, for example, LUCKY having a smaller, smoother movement than VERY-LUCKY. The movement changes conveying temporal aspect 
are frequently visually motivated, so that repeated actions or events are shown through repetition of the sign; duration of an event is paralleled by duration of the sign (signs for shorter events being articulated for less time than signs for longer events); and when an event is interrupted suddenly, the movement of the sign is interrupted.

\section{Syntax}

As discussed above, sign languages exploit the possibilities afforded by multiple articulators. Simultaneous syntactic structures include, for example, producing the head of a noun phrase on the non-dominant hand and the modifier on dominant hand; argument maintenance on the non-dominant hand; and duplication of a verb on two hands for reciprocal action (e.g., LOOK (one-handed) versus LOOK-AT-EACH-OTHER (two-handed)).

Differences between BSL sign order and English word order were noted in the early 19th century in a gloss of the Lord's Prayer in BSL:

Father our, heaven in, name thy hallowed. Kingdom thy come - will thy done - earth on - heaven in - same. Bread give us daily - trespasses our forgive us - they trespass against us, forgive - same. Temptation lead not - but evil deliver from. Kingdom - power - glory thine forever.

(Hippisley Tuckfield 1839)

\section{Visual prosody}

Facial actions, including movements of the brows, eyes, mouth and head, are used in sign languages to mark prosodic contrasts. For example, wh-questions ('Who's the man in the blue shirt?') and yes/no questions ('Was there a researchers' meeting yesterday?' versus 'There was a researchers' meeting yesterday'), conditionals ('If I go to the doctor's tomorrow, the meeting will be cancelled' versus 'I am going to the doctor's tomorrow, so the meeting is cancelled') and topicalisation ('As for my book, it will be published this year'). These facial actions are temporally coordinated with specific parts of the sentence

\section{Bilingualism in signing communities}

In common with most minority languages in close contact with a majority language, sign languages are often influenced by majority languages. It is rare to find signers in Europe and North America who are not bilingual in their sign language and the majority language. For some signers, this means using signing 
and a written form of the spoken language. Other signers may also use the spoken language and lip-read.

Until recently, studies of bilingualism considered only individuals and communities in which two spoken languages are used. With the development of research on sign languages, it has become clear that bilingualism can be bimodal as well as unimodal. Unimodal bilingualism occurs when either two spoken or two sign languages are used (e.g., Irish Sign Language and British Sign Language); bimodal bilingualism occurs when the two languages exist in different modalities: one signed and one spoken/written. Recognition of bimodal bilingualism has led to a re-evaluation of models of bilingualism.

Sign languages are able to accommodate spoken languages visually in various ways. One widespread method is the use of fingerspelling by means of manual alphabets. Manual alphabets use distinct hand configurations to represent each letter of a written alphabet, enabling the signer to recreate the spelling of any written word using that alphabet. Different sign languages use fingerspelling to different extents. Figures 6 and 7 below illustrate the British manual alphabet and its use contrasted to signing.

Many European sign languages and ASL have signs with handshapes derived from manual letters. For example, in ASL the signs GROUP, TEAM, FAMILY

\section{British Sign Language Alphabet}
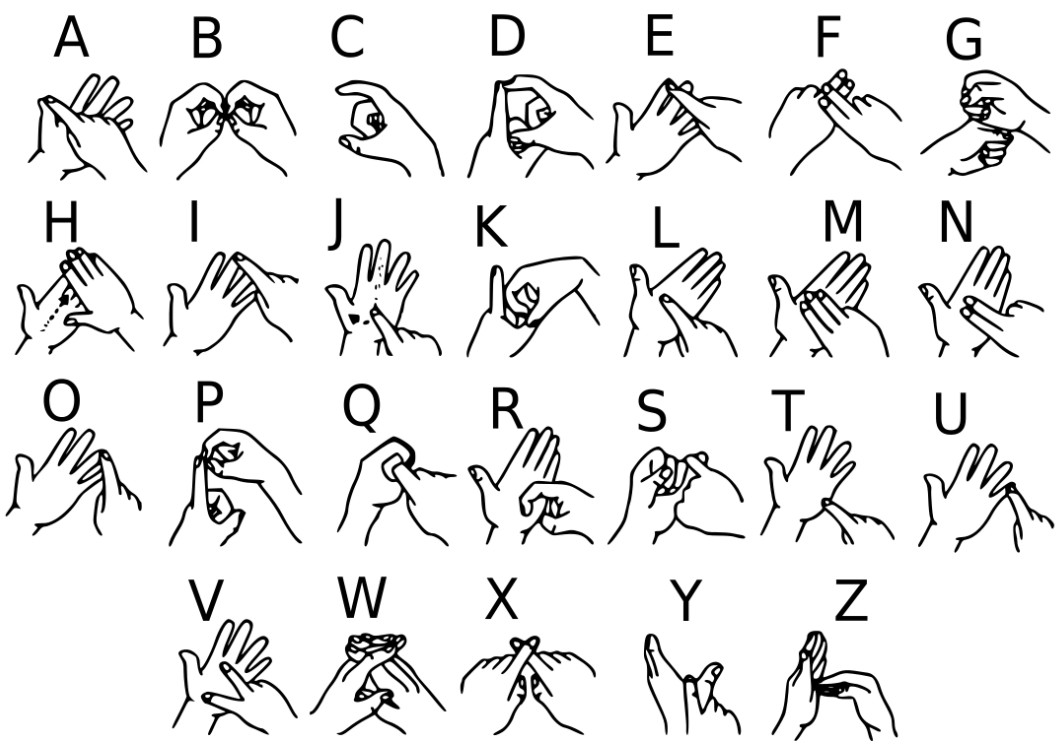

Figure 6: British two-handed manual alphabet (Public domain). 

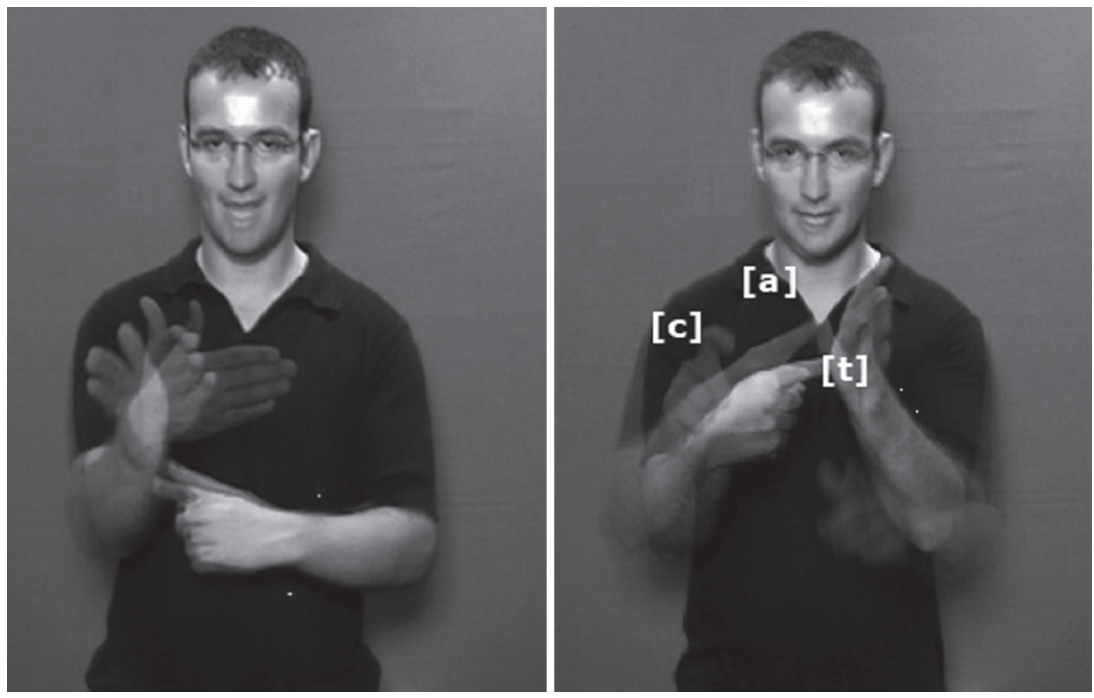

Figure 7: Contrast between sign FLAG, with single handshape, location and movement; and fingerspelled c-a-t-, with three different handshapes and configurations representing English orthography (From: Atkinson et al. (in prep): Hand dominance and language: Insights from a British sign language user following left-hemisphere stroke. Reprinted by permission of authors).

and ASSOCIATION have handshapes borrowed from the letters -g-, -t-, -fand -a-, respectively, but the movement and location of the signs are otherwise identical. In Irish Sign Language, the signs HAPPY, HEARING and HOUR all have the same -h- handshape, although the movements and locations of the signs differ. Fingerspelling may be used to represent words for which the sign language does not have a well-established sign, or where a sign has only local use. Then fingerspelling can act as a form of lingua franca for signers from all regions. This is common, for example, in the use of place names. In some cases fingerspellings become adapted to the phonology of the sign languages and are used as established loanwords. Battison (1978) described in detail the phonological changes that fingerspellings in ASL undergo to become loanwords in ASL. These changes include reduction of the number of letters to an ideal number of two and assimilation of handshape and movement between the letters. Similar processes occur in BSL (Sutton-Spence, Woll \& Allsop 1990). BSL also makes use of single manual letter signs as established loanword signs. For example, the manual component of the signs MOTHER, MONDAY, TUESDAY, TOILET, AUTOMATIC and ALCOHOLIC in many BSL dialects consists of the fingerspelled first letter of each English word (that is, -m-m- is used for 'mother' and 'Monday' and -a-a- for 'automatic' and 'alcoholic'). 
These single manual letter signs can have several potential homonyms. Context serves to distinguish between the manual homonyms, but in many sign languages, especially where the signers know the spoken language of the wider community, the mouth action derived from the spoken word equivalent is also articulated, both for fingerspelling-derived signs and for other signs. Thus the sign MOTHER using -m-m- is accompanied by mouthing of the English word 'mother', and BATTERY and UNCLE are distinguished by their respective mouthings. Mouthings are commonly used in European sign languages, and to a lesser extent in ASL, not only to distinguish between homonyms but more generally (Boyes-Braem \& Sutton-Spence 2001). The use of these spoken language mouthings together with signs is an example of codemixing specific to cross-modal bilingualism, since only sign languages allow the articulation of forms from two languages simultaneously, and is known as code-blending.

\section{Borrowing from sign languages}

Although sign languages borrow most extensively from the spoken languages of the wider hearing community, they also borrow from other sign languages. BSL and Irish Sign Language borrow from each other, owing to cultural and geographical closeness. Signers of ISL have considerable access to BSL, both through television broadcasts of British television programmes for deaf viewers that can be received in Ireland and through the ease of movement for social and employment purposes between Ireland and England. Borrowing may also occur on a larger scale through educational practice. Richer countries, such as the USA, Finland, Denmark and Britain, with teacher training facilities and Deaf Studies departments at university level, may train people from poorer countries with less well developed education and Deaf Studies facilities of their own. When they return to their own countries, graduates take with them influences from European and American sign languages (see, e.g., Schmaling 2003). As with all languages in contact, there is influence on sign languages from surrounding spoken languages, either through natural processes of borrowing (see below) or the use in schools of artificial communication systems such as 'Signed English' or 'Signed Dutch'.

\section{Language change and technology}

Social and technological changes are having a substantial effect on BSL and other sign languages. It must remembered that there was no BSL on television until after 1980. Now several hours of sign language are broadcast daily (mostly in the form of sign language interpretation of mainstream programming); there 
is an ever increasing number of signed videos on the internet; and remote faceto-face interaction via Skype and Facetime is now common. As documentation of sign language increases, previously substantial regional variation in BSL is reducing rapidly.

Sign language dictionaries are usually created to collect and preserve the lexicon of the language or to allow others to learn the language. Most SL 'dictionaries' are more accurately 'bilingual word lists' using a written language and illustrations of signs. Signs are rarely defined using the sign language and are more often defined through the written language. Some specialist bilingual dictionaries offer translations of words and signs used in specific trades or scholarly areas (for example, see www.artsigns.ac.uk).

Dictionaries of minority languages often aim to document the endangered language, be a reference dictionary for less fluent speakers, be a teaching tool, standardise the language, and 'celebrate' the language. They often provide 'a clear and powerful symbolic function of recognition and empowerment on the language' (Lucas 2002) but can also threaten the language if the making of the dictionary is not carefully controlled (Armstrong 2003), especially if the language description is perceived prescriptively. Signs that are in dictionaries are more likely to be accorded high status, be considered 'standard' and be in more widespread use than those that are omitted. Dictionaries have relatively little direct impact on native signers, because they rarely use them, but second language learners of sign languages who use these dictionaries often become educators or interpreters and may ultimately have considerable power within the sign language community.

Recent advances in technology have allowed construction of signed corpora (cp. BSL Corpus Project https://bslcorpusproject.org/). Signed corpora are still small, but corpus-based dictionaries are also now available (cp. BSL SignBank http://bslsignbank.ucl.ac.uk/). Corpora allow researchers to identify sign frequencies so that teaching materials can be better designed and are also of great importance in developing automated translations.

\section{Learning sign language as an L1}

It is beyond the scope of this chapter to discuss research on sign language acquisition as an L1. There is general agreement that sign language acquisition parallels that of spoken language when young children (deaf or hearing) are exposed to sign language by deaf parents. However, most deaf children's exposure to language is very different from that of hearing children learning a spoken language. The typical experience for deaf children is late exposure to a first language, even in the context of cochlear implantation (Mayberry \& Squires 2006). Herman and Roy (2006) found that many deaf children do not achieve age-appropriate levels of BSL, and the majority of deaf children also do not achieve age-appropriate levels of spoken/written language. 


\section{Learning sign language as an L2}

There have been substantial changes in the attitudes of the general public to sign language since the 1980s, particularly in the representation of sign languages in the media. This has been accompanied by an enormous increase in the number of hearing people learning sign language (there are significantly more hearing people with some knowledge of BSL than the number of members of the deaf community). There is current interest in offering sign languages as modern languages within the general school population. France announced in July 2009 that it would introduce LSF into the Baccalaureate system; in England, a pilot GCSE course ran in 2015, and the Department for Education has agreed to offer a BSL GCSE. Universities in the UK and other countries recognise sign languages as meeting their modern language requirements. In the USA, ASL is the second most popular modern language studied by undergraduates after Spanish.

The increased interest in learning sign language has implications for teacher training and language resources, as training for sign language teachers is often very limited or non-existent.

\section{Sign language interpreting}

In the past the 'go-between' for hearing and deaf people was traditionally a hearing member of a deaf person's family or a 'missioner' - a church or voluntary worker with the deaf. As connections between deaf communities and the church weakened, this task was taken on by social workers for the deaf (Brennan \& Brown 1997). (The BSL sign SOCIAL-WORKER is derived from the old sign MINISTER). Professional BSL/English interpreting began in the early 1980s. Interpreters now undergo formal linguistic and interpreting training. Unfortunately, the shortage of interpreters is a serious problem, since they enable access to communication with the hearing world. Laws requiring sign language provision in public settings (such as on television or for health and legal settings) do not take into account the shortage of qualified, experienced interpreters. There is also a shortage of deaf interpreters, who often work as 'relay' interpreters in situations where a deaf person (for example, in court) may not understand the signing of a hearing interpreter, who in turn may not understand the deaf person. In such situations a deaf relay interpreter may be called upon to act as an interface between the interpreter and the deaf client (Brennan \& Brown 1997). Increasingly, deaf interpreters also work in the media, providing sign language translations of pre-recorded programmes or pre-prepared live programmes.

A frequently proposed solution to the chronic shortage of interpreters is automated BSL-to-English translation and the use of computer-generated signing avatars. Such systems are still in early stages of development and - despite 
press reports - need much further work, including linguistic research, and access to sign language corpora

\section{Conclusions}

Where will the field go next? A review and re-examination of the educational experiences and achievements of deaf children is overdue, as is research to underpin policy developments in relation to education, legal rights to interpreting, accessibility requirements for broadcasters and employment rights. New training programmes for the teaching of BSL in schools and universities and for deaf classroom assistants, sign language therapy assistants and interpreters (both deaf and hearing) are needed.

The history of sign languages, like that of many minority languages, cannot be separated from a study of their relationship with the majority language communities which surround them. At the beginning of the 21st century, there are contrasting futures: pressures, such as the decrease in opportunities for deaf children to use sign language with their peers as a result of the shift to mainstream education and the possible decrease in the deaf population as a result of medical intervention and advances in genetics; while, at the same time, there is increased interest and demand from the hearing community for courses in sign language, increased use of sign language in public contexts and increased pride of the deaf community in their distinctive language and culture. It is to be hoped and expected that sign languages will continue to be living languages. Applied linguistics has a great deal to contribute.

\section{References}

Aarons, D. and Akach, P. 1998 South African Sign Language - one language or many? A sociolinguistic question. Stellenbosch Papers in Linguistics, 31: $1-28$.

Armstrong, D. 2003 Introduction to special issue on dictionaries and lexicography, Part II: The development of national sign language dictionaries. Sign Language Studies, 3: 378.

Atkinson, J., Marshall, J., Sharma, S. and Woll, B. (in preparation) Hand dominance and language: Insights from a British sign language user following left-hemisphere stroke.

Battison, R. 1978 Lexical borrowing in American Sign Language. Silver Spring, MD: Linstok Press.

Boyes-Braem, P. and Sutton-Spence, R. 2001 (eds) The hands are the head of the mouth. Hamburg: Signum-Verlag.

Branson, J., Miller, D., Marsaja, I.G. and Negara, I.W. 1996 Everyone here speaks sign language, too: A deaf village in Bali, Indonesia. In Lucas, C. 
(ed.), Multicultural aspects of sociolinguistics in deaf communities. Washington, DC: Gallaudet University Press. pp. 39-60.

Brennan, M. and Brown, R. 1997 Equality before the law: Deaf people's access to justice. Durham: Deaf Studies Research Unit.

Brentari, D. 2011 Sign language phonology. In Goldsmith, J., Riggle, J. and $\mathrm{Yu}$, A.C.L. (eds), The handbook of phonological theory. Oxford: Blackwell. pp. 691-721.

Bulwer, J. 1648 Philocophus. London: R Whitaker.

Burns, S. 1998 Irish Sign Language: Ireland's second minority language. In Lucas, C. (ed.), Pinky extension and eye gaze: Language use in deaf communities. Washington, DC: Gallaudet University Press. pp. 233-273.

Carew, R. 1602 The Survey of Cornwall. London: E. Law.

Emmorey, K., Corina, D. and Bellugi, U. 1995 Differential processing of topographic and referential functions of space. In Emmorey, K. and Reilly, J. (eds), Language, gesture and space. Hillsdale, NJ: Lawrence Erlbaum Associates. pp. 43-62.

Engberg-Pedersen, E. 1993 Space in Danish Sign Language. Hamburg: Signum Press.

Ferreira-Brito, L. 1985 A comparative study of signs for time and space in São Paulo and Urubu-Kaapor Sign Language. In Stokoe, W. and Volterra, V. (eds), Proceedings of the 3rd International Symposium on Sign Language Research 1983. Rome/Silver Spring, MD: CNR/Linstok Press. pp. 262-268.

Fischer, S. 1978 Sign language and creoles. In Siple, P. (ed.), Understanding language through sign language research. New York: Academic Press. pp. 209-331.

Herman, R. and Roy, P. 2006 Evidence from the extended use of the BSL Receptive Skills Test. Deafness \& Education International, 8(1): 33-47.

Hippisley Tuckfield, C. 1839 Education for the people. London: Taylor and Walton. Johnson R.E. 1994 Sign language and the concept of deafness in a traditional Yucatec Mayan village. In Erting, C.J., Johnson, R.E., Smith, D.L. and Snider, B.D. (eds), The Deaf Way - Perspectives from the International Conference on Deaf Culture, 1989. Washington, DC: Gallaudet University Press. pp. 102-109.

Kegl, J.A., Senghas, A. and Coppola, M. 1999 Creation through contact: Sign language emergence and sign language change in Nicaragua. In DeGraff, M. (ed.), Comparative grammatical change: The intersection of language acquisition, creole genesis, and diachronic syntax. Cambridge, MA: MIT Press. pp. 179-238.

Kendon, A. 1980 A description of a deaf-mute sign language from the Engaprovince of Papua New Guinea with some comparative discussion: Parts I, II, III. Semiotica, 32: 1-34, 81-117, 245-313.

Kisch, S. 2007 Disablement, gender and deafhood among the Negev ArabBedouin. Disability Studies Quarterly, 27(4). Available from http://www. dsq-sds.org/article/view/45/45 
Kisch, S. 2008 'Deaf discourse': The social construction of deafness in a Bedouin community. Medical Anthropology, 27(3): 283-313.

Kusters, A. 2009 Deaf utopias? Reviewing the sociocultural literature on the world's 'Martha's Vineyard situations'. Journal of Deaf Studies and Deaf Education, 15(1): 3-16.

Kyle, J.G. and Woll, B. 1985 Sign language: The study of deaf people and their language. Cambridge: Cambridge University Press.

Lane, H. 1984 When the mind hears: A history of the deaf. New York: Random House.

Lane, H., Hoffmeister, R. and Bahan, B. 1996 A journey into the deaf world. San Diego, CA: Dawn Sign Press.

Lucas, C. 2002 The role of variation in lexicography. Sign Language Studies, 3: 322-340.

MacSweeney, M., Waters, D., Brammer, M.J., Woll, B. and Goswami, U. 2008 Phonological processing in deaf signers and the impact of age of first language acquisition. Neuroimage, 40: 1369-1379.

MacSweeney, M., Woll, B., Campbell, C., McGuire, P.K., Calvert, G.A., David, A.S., Williams, S.C.R. and Brammer M.J. 2002 Neural systems underlying British Sign Language sentence comprehension. Brain, 125: 1583-1593.

Mathur, G. and Rathman, C. 1998 Why not 'GIVE-US': An articulatory constraint in signed languages. In Dively, V., Metzger, M., Taub, S. and Baer, A.-M. (eds), Signed Languages: Discoveries from international research. Washington, DC: Gallaudet University Press. pp. 1-26

Mayberry, R.I. and Squires, B. 2006 Sign language acquisition. In Lieven, E. (ed.), Language acquisition, Vol. 11, Encyclopedia of language and linguistics. 2nd ed. Oxford: Elsevier. pp. 291-295.

Meier, R., Cormier, K. and Quinto-Pozos, D. 2003 Modality and structure in signed and spoken languages. Cambridge: Cambridge University Press.

Nichols, J. 1992 Linguistic diversity in space and time. Chicago, IL: University of Chicago Press.

Pepys S. 1666 Diary entry for 9 November 1666. Available at http://www.pepys. info/1666/1666nov.html

Schermer, G. 2004 Lexical variation in Sign Language of the Netherlands. In van Herreweghe, M. and Vermeerbergen, M. (eds), To the lexicon and beyond: Sociolinguistics in European deaf communities. Washington, DC: Gallaudet University Press. pp. 91-110.

Schmaling, C. 2003 A for apple: The impact of western education and ASL on the deaf community in Kano State, Northern Nigeria. In Monaghan, L., Schmaling, C., Nakamura, K. and Turner, G. (eds), Many ways to be deaf: International variation in deaf communities. Washington, DC: Gallaudet University Press. pp. 302-310.

Slobin, D. 2005 Issues of linguistic typology in the study of sign language development of deaf children. In Schick, B., Marschark, M., and Spencer, P. (eds), Sign language development of deaf and hard-of-hearing children: Where 
have we been, and where are we going? Oxford: Oxford University Press. pp. 20-45.

Stokoe W.C. 1960 Sign language structure: The first linguistic analysis of American Sign Language. Silver Spring, MD: Linstok Press.

Supalla, T. 1986 The classifier system in American Sign Language. In Craig, C. (ed.), Noun classes and categorization (Typological Studies in Language 7). Amsterdam: John Benjamins. pp. 181-214

Sutton-Spence, R., Woll, B. and Allsop, L. 1990 Variation in fingerspelling in BSL. Language Variation and Change, 2(3): 315-332.

Taub, S. 2001 Language from the body: Iconicity and metaphor in American Sign Language. Cambridge: Cambridge University Press.

Vermeerbergen M., Leeson L. and Crasborn, O. (eds) 2007 Simultaneity in signed languages. Amsterdam/Philadelphia, PA: John Benjamins.

Washabaugh W. 1981 The deaf of Grand Cayman, British West Indies. Sign Language Studies, 31: 117-133.

Woodward J. 1996 Modern standard Thai Sign Language, influence from ASL, and its relationship to original Thai sign varieties. Sign Language Studies, 25: 225-252. 